Islands of the Inner Hebrides, Harker set a high standard of work both in the field and in the laboratory. His book on the "Natural History of Igneous Rocks", published in 1909, has been described as "a work which has had a greater effect than any geological publication in the last fifty years". $\mathrm{He}$ has also made contributions of great value to the subject of differentiation of rock magmas, etc. His latest book on "Metamorphism", published in 1932, is the best contribution to the subject written in any language.

\section{Davy Medal, awarded to Prof. A. Harden}

Prof. Arthur Harden is awarded the Davy Medal in recognition of his distinguished work in biochemistry and especially of his fundamental discoveries in the chemistry of alcoholic fermentation. In 1904, in collaboration with his colleague W. J. Young, he showed that the alcoholic ferment of active cell-free yeast juice, the preparation of which had been achieved a few years earlier by $\mathrm{E}$. and $\mathrm{H}$. Buchner, could be separated into two components, a thermolabile non-dialysable enzyme complex and a thermostable dialysable co-enzyme, both of these being essential for the fermentation of sugar. They observed that the fermentation of sugars by this yeast juice was profoundly affected by an addition of inorganic phosphate, and followed up this dis. covery by a detailed and systematic investigation of the carbon balance, from which they showed that, for each hexose molecule broken down to carbon dioxide and alcohol, another molecule became esterified with phosphoric acid. From the fermentation products, hexosediphosphoric and hexosemonophosphoric esters were afterwards isolated by Harden and his colleagues. These discoveries have been the foundation upon which much of our present knowledge of the intermediate changes in the enzymic breakdown of carbohydrate has been established.
Harden has made important contributions to our knowledge of chemical reactions effected by bacterial enzymes, especially those concerned in carbohydrate metabolism. He has also taken an active part in the development of vitamin research in Great Britain, while as editor of the Biochemical Journal since 1911 he has influenced deeply the development of this branch of chemistry.

\section{Hughes Medal, awarded to Dr. C. J. Davisson}

A Hughes Medal is awarded to Dr. Clinton Joseph Davisson for his discovery that electrons are diffracted like waves of light. Like many other discoveries, this one disclosed itself gradually; but its origin can certainly be traced to some experiments on the scattering of electrons by nickel made by Davisson and Kunsmann in 1921. Davisson recognised at the time that the observed effects did not harmonise with the existing theories of matter and electrons. Owing to the polycrystalline nature of the metals investigated, the correct interpretation to be put upon the results was not at all clear. Davisson fully recognised the importance of this discrepancy, and this he and his assistants proceeded to investigate with great pertinacity and skill.

Towards the end of 1926, Davisson and Germer succeeded in making similar experiments with a single metallic crystal surface, so that the results were simple enough to be interpreted easily. It was then at once seen that the electrons were diffracted like waves of light of the wave-length required by the theory which had in the meanwhile been put forward by M. de Broglie towards the end of 1924 . The first announcement of Davisson and Germer's results was published in Nature of April 16, 1927. This publication was the first clear experimental proof of the wave character of the electron.

Davisson has also made important contributions to thermionics.

\title{
Thixotropic Colloids
}

A PUBLIC lecture on some recent developments of colloid science was delivered at Queen Mary College, London, on November 29 by Prof. H. Freundlich.

Prof. Freundlich pointed out that, whilst it has long been known that a solid gel, such as a gelatin gel, may be liquefied to a sol on heating, and that it returns reversibly to the state of a gel on cooling, investigators in colloid science scarcely realised until recently that an isothermal, reversible, sol-gel transformation is also very frequent. Many gels may be liquefied by shaking or stirring and set to a gel again, in a definite time, when left to themselves. This phenomenon is called thixotropy. It is found not only in true sols and gels (of oxides like $\mathrm{Al}_{2} \mathrm{O}_{3}$, $\mathrm{Fe}_{2} \mathrm{O}_{3}$, of gelatin, etc.), but also in concentrated suspensions of coarser particles (of clays, bentonite, etc.). In many cases, thixotropy may be regarded as a first, reversible stage of coagulation, causing the whole sol to unite to one large flake, so to say, which is able to enclose all the liquid present.

Under suitable conditions, some thixotropic sols may be solidified much more rapidly by a gentle, regular movement, a phenomenon called rheopexy. Thus there is a distinct difference between the liquefying action of strong and irregular movement and the solidifying influence of regular, weak vibra. tions and similar kinds of movement.

Thixotropy generally, perhaps always, involves a loose packing of the particles. The plastic behaviour of such masses also depends upon their loose packing. Hence thixotropy and plasticity are in opposition to Osborne Reynolds's dilatancy, which involves close packing; moist, pure quartz sand shows dilatancy, becoming hard and dry when displaced by an external force, and returning to its original, moist state when this force ceases to act. Foreign substances, such as clay, etc., when added to the sand, form waterbinding layers round the particles, thus causing loose packing and thixotropy. A case of quicksand was found the thixotropic behaviour of which was caused by the presence of a fine, clay-like substance; this may be a fairly frequent occurrence. Moulding sands are also plastic and thixotropic because they contain clay and iron compounds.

In many other technical processes (plastics, paints, drilling fluids in the petroleum industry, etc.) thixotropy turns out to be an important factor. Protoplasm is frequently thixotropic, or may readily become so in the course of biological processes. 